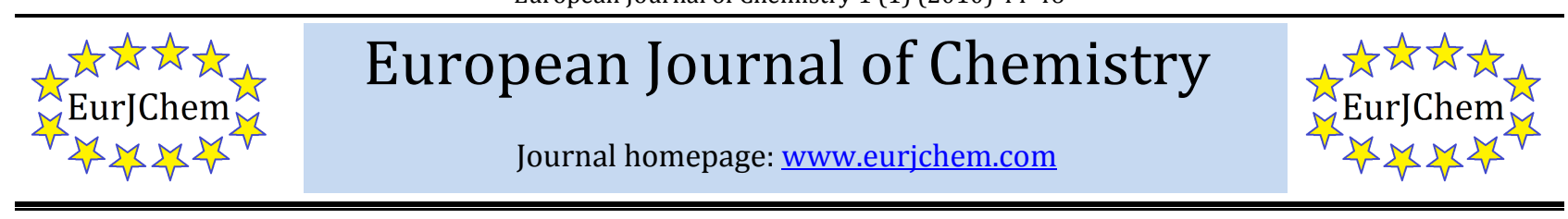

\title{
Effect of calcitonin on lipid peroxidation in ovariectomized rats
}

\author{
Mehmet Berkoza, Serap Yalin ${ }^{b}$, Ulku Comelekogluc and Selda Bagis ${ }^{\mathrm{d}}$ \\ a Department of Pharmaceutical Technology, Faculty of Pharmacy, Mersin University, Mersin, TR-33343, Turkey \\ ${ }^{b}$ Department of Biochemistry, Faculty of Pharmacy, Mersin University, Mersin, TR-33343, Turkey \\ c Department of Biophysics, Medical School, Mersin University Mersin, TR-33343, Turkey \\ d Department of Physical Medicine and Rehabilitation, Medical School, Baskent University, Adana, TR-01150, Turkey \\ *Corresponding author at: Department of Biochemistry, Faculty of Pharmacy, Mersin University, Mersin, TR-33343, Turkey. Tel.: +90.530.6878967; fax: \\ +90.324.3413022. E-mail address: syalin01@hotmail.com (S. Yalin).
}

\section{ARTICLE INFORMATION}

Received: 1 February 2010

Received in revised form: 2 March 2010

Accepted: 5 March 2010

Online: 31 March 2010

\section{KEYWORDS}

\section{Osteoporosis}

Oxidative stress

Antioxidant

Ovariectomy

Calcitonin

\begin{abstract}
Calcitonin is one of the active substances which is recently used effectively in osteoporosis treatment. In literature there is no information whether calcitonin cause oxidative stress or not. In this study, subcutaneous calcitonin is applied to rats having experimental postmenopausal osteoporosis and the effects of calcitonin on lipid peroxidation and antioxidant system were investigated. Forty-five healthy adult female Swiss albino Wistar rats were used in this study. The rats were divided into three equal groups as control, ovariectomized (Ovx) and ovariectomized+calcitonin (Ovx-CAL). The rats in Ovx and OvxCAL were anaesthetized and underwent a bilateral ovariectomy via ventral incision. Ten weeks after ovariectomy, salmon calcitonin ( $2 \mathrm{IU} / \mathrm{kg}$ body weight) was administered via s.c. at a volume of $1 \mathrm{~mL}$ per week for 12 weeks to the Ovx-CAL group. At the end of the drug treatment, livers and kidneys of rats were removed and malondialdehyde (MDA) levels and catalase (CAT) activities were determined by biochemical analysis methods. Data were analyzed by one-way ANOVA followed by the post-hoc LSD multiple test. The liver and kidney MDA levels were increased whereas the activity of CAT enzyme was decreased as a result of ovariectomy compared to values in the control group. Similar results were observed in OvxCAL group; however, the decline in the CAT activity in the kidney was not significant. In conclusion, we may suggest that calcitonin treatment increases the oxidative stress in osteoporotic rats.
\end{abstract}

\section{Introduction}

Osteoporosis-means porous bone in Greek- is a disease that is characterized by structural disruption of bone and low bone mass. Low bone mass can cause bone fragility and fractures [1]. Osteoporosis can be a debilitating disease that can result in chronic pain, fractures, inability to participate in normal daily activities, depression, social withdrawal, loss of independence, and deformities [1,2]. Although osteoporosis is observed mostly in women, it can also affect men. Osteoporosis can occur at any age and in any racial or ethnic group, though it is more common in the postmenopausal women [1-4]. Pharmacologic interventions for the prevention and treatment of osteoporosis include vitamin and mineral supplementation, hormone replacement therapy, bisphosphonates, and selective estrogen receptor modulators, fluoride supplementation and salmon calcitonin $[5,6]$.

Salmon calcitonin inhibits bone resorption via blocking osteoclastic activity. However, the mechanisms by which these medications exert their protective effects on bone are not clear, though it is generally accepted that calcitonin exerts a direct inhibitory action on mature osteoclasts [7]. There is evidence that markers of bone turnover decrease and that bone mineral density stabilizes with the use of calcitonin. Calcitonin is indicated for the treatment of postmenopausal osteoporosis, Paget's disease, and hypercalcemia [7-9].

Some of the risk factors for osteoporosis are advanced age, beeing Caucasian or Asian, endocrine disorders, family history of osteoporosis, high/excessive intake of some vitamins and minerals, impaired calcium and/or vitamin D absorption, low calcium and/or vitamin D intake or other minerals/vitamins, low exposure to sunlight, low levels of testosterone/estrogen propensity for falls and smoking [10-13]. Furthermore, reactive oxygen species (ROS) induced oxidative stress has been associated with the pathogenesis of osteoporosis. Some studies reported that certain antioxidants can decline the risk of osteoporosis. Women with osteoporosis have markedly decreased plasma antioxidants. Increased oxidative stress biomarker is linked with reduced bone density [14-16]. Despite these, the role of oxidative stress in osteoporosis was not properly explained [15]

Although the effects of oxidative stress on osteoporosis has been well documented, the effects of salmon calcitonin treatment on oxidative stress in osteoporotic subjects is not clear $[14,15]$. The aim of this study was to investigate the effects of calcitonin treatment on oxidative stress in postmenopausal osteoporosis. We used ovariectomized rat model for creating the post-menopausal osteoporosis model.

\section{Experimental}

\subsection{Animals}

Forty-five healthy adult female Swiss albino Wistar rats (10-12 weeks of age and average body weight of 200-250 g) were used in this study. The animals were acclimatized for 1 
week to our laboratory conditions prior to experimental manipulation and were exposed to a 12 -h light and 12 -h dark cycle at room temperature of $22 \pm 1^{\circ} \mathrm{C}$. They had free access to standard laboratory chow and water ad libitum. The rats were divided into three groups; I, control $(n=15)$; II, ovariectomized (Ovx, $n=15$ ); and III, ovariectomized+calcitonin (Ovx-CAL, $n=15$ ). The rats in the control group were neither operated on nor treated with calcitonin. All animal procedures used were in strict accordance with the National Institutes of Health Guidelines on the Care and Use of Laboratory Animals, and the approval of the ethic committee of the School of Medicine, Mersin University was obtained prior to the study.

\subsection{Surgical procedures}

The rats in Ovx and Ovx-CAL were anaesthetized with ketamine $(50 \mathrm{mg} / \mathrm{kg}$, Ketalar, Eczacıbașı) and xilacine (8 $\mathrm{mg} / \mathrm{kg}$, Rompun, Parke-Davis/Pfizer) and underwent a bilateral ovariectomy via ventral incision. Ovaries were excised and oviducts were replaced, with minimum disruption to surrounding soft tissues, and the incisions were closed with clips.

\subsection{Treatment process and tissue preparation}

Ten weeks after ovariectomy, salmon calcitonin was diluted in $0.9 \% \mathrm{NaCl}$ solution to obtain the dose of $2 \mathrm{IU} / \mathrm{kg}$ body weight and administered via s.c. at a volume of $1 \mathrm{~mL}$ per week for 12 weeks to the Ovx-CAL group. Control and Ovx groups didn't take any treatment during that period and took standard feeding. At the end of the $12^{\text {th }}$ week, the rats in all groups were sacrificed by decapitation under ketamine anesthesia. The livers and kidneys were quickly excised, rinsed in ice-cold $0.175 \mathrm{M} \mathrm{KCl} / 25 \mathrm{mM}$ Tris- $\mathrm{HCl}(\mathrm{pH}$ 7.4) to remove the blood, weighed, finely minced in the same solution, and homogenized by means of homogenizer with a Teflon pestle. Then, the liver and kidney homogenates were centrifuged at $10,000 \mathrm{~g}$ for 15 min at $4{ }^{\circ} \mathrm{C}$. Supernatants were separated and kept at $-20^{\circ} \mathrm{C}$ until enzyme activity and malondialdehyde (MDA) measurements were performed.

\subsection{Biochemical assay}

Lipid peroxidation: Liver and kidney MDA levels, as an index of lipid peroxidation, were determined by thiobarbituric acid reaction according to the Yagi method [17]. This method relies on the measurement of the pink color produced by interaction of thiobarbituric acid with MDA elaborated as a result of lipid peroxidation. The colored reaction of 1,1,3,3-tetraethoxyn propane was used as the primary standard.

Enzyme assay: Catalase (CAT) activity of tissues was determined according to the method of Aebi et al. [18]. The enzymatic decomposition of $\mathrm{H}_{2} \mathrm{O}_{2}$ was followed directly by the decrease in absorbance at $240 \mathrm{~nm}$. The difference in absorbance per unit time was used as a measure of CAT activity. Specific activity was defined as micromole of substrate decomposed per minute per milligram of protein as $\mathrm{U} / \mathrm{mg}$ protein.

Determination of protein content: Tissue protein content was determined according to the method developed by Lowry et al. [19] using bovine serum albumin as standard.

\subsection{Statistical analysis}

All assays were performed in duplicate and the mean was used for statistical analysis. All analyses were performed using the Statistical Package for the Social Sciences (SPSS) Windows version 16.0 software in a PC-compatible computer. Results are expressed as mean \pm SD. Normality of distribution was assessed by Kolmogorov-Smirnov test. Data were analyzed by one-way ANOVA followed by the post-hoc LSD multiple test. $p<0.05$ was considered statistically significant.

\section{Results}

\subsection{Liver}

The liver MDA levels doubled $(\mathrm{p}<0.05)$, whereas the activity of antioxidant enzyme CAT decreased by $40 \%(\mathrm{p}<0.05)$, as a result of ovariectomy compared to the values of the control group. In Ovx-CAL group, MDA level increased 3.8 fold, whereas CAT activity decreased by $67.3 \%$, compared to the control group. In the comparison of the Ovx and Ovx-CAL groups, we found that MDA level was significantly higher - about 1.85 times $(\mathrm{p}<0.05)$ - and CAT activity was significantly lower (by $46 \%$; $\mathrm{p}<0.05$ ) in the Ovx-CAL group than those of the Ovx group (Table 1).

Table1. Liver MDA concentration and CAT activity in control, Ovx and OvxCAL groups.

\begin{tabular}{llll}
\hline Variables & Control $(\boldsymbol{n}=15)$ & Ovx $(\boldsymbol{n}=15)$ & Ovx-CAL $(\boldsymbol{n}=15)$ \\
\hline $\begin{array}{l}\text { MDA } \\
\text { (nmol/mg protein) }\end{array}$ & $0.51 \pm 0.10$ & $1.05 \pm 0.14^{\mathrm{a}}$ & $1.94 \pm 0.51^{\mathrm{a}, \mathrm{b}}$ \\
$\begin{array}{l}\text { CAT } \\
\text { (U/mg protein) }\end{array}$ & $190.15 \pm 10.61$ & $114.21 \pm 12.34^{\mathrm{a}}$ & $62.21 \pm 15.49^{\mathrm{a}, \mathrm{b}}$ \\
\hline a Significantly different from control at $\mathrm{p}<0.05$. &
\end{tabular}

a Significantly different from control at $\mathrm{p}<0.05$.

b Significantly different from Ovx group at $\mathrm{p}<0.05$.

\subsection{Kidney}

As shown in Table 2, ovariectomy resulted in an increase in the MDA level (approximately 1.8 fold, $\mathrm{p}<0.05$ ) compared to the control, but there was no significant difference in the activity of CAT in the kidneys of control and Ovx groups ( $p>0.05$ ). In the comparison of the Ovx and Ovx-CAL groups, we found that MDA level was significantly higher - about 1.4 times $(\mathrm{p}<0.05)$ - but no significant variation in CAT activity was observed between the Ovx and Ovx-CAL groups (Table 2).

Table 2. Kidney MDA concentration and CAT activity in control, Ovx and Ovx-CAL groups.

\begin{tabular}{llll}
\hline Variables & Control $(\boldsymbol{n}=15)$ & Ovx $(\boldsymbol{n}=15)$ & Ovx-CAL $(\boldsymbol{n}=15)$ \\
\hline $\begin{array}{l}\text { MDA } \\
\text { (nmol/mg protein) }\end{array}$ & $0.85 \pm 0.20$ & $1.55 \pm 0.17 \mathrm{a}$ & $2.19 \pm 0.43^{\mathrm{a}, \mathrm{b}}$ \\
$\begin{array}{l}\text { CAT } \\
\text { (U/mg protein) }\end{array}$ & $210.21 \pm 18.71$ & $190.11 \pm 10.38$ & $182.33 \pm 16.59$
\end{tabular}

(U/mg protein) $\quad 210.21 \pm 18.71 \quad 190.1$

b Significantly different from Ovx group at $\mathrm{p}<0.05$.

\section{Discussion}

In our study we investigated the effect of post-menopausal calcitonin treatment on oxidative stress in rat liver and kidney tissues. We measured the MDA level and CAT activity to evaluate the oxidative stress. We found that MDA levels increased in liver and kidney tissues and CAT activity decreased in liver but not in the kidney of ovariectomized rats compared to control group. Reports about the effect of ovariectomy on antioxidant enzymes and lipid peroxidation are conflicting. Kume-Kick et al. indicated that gonadectomy was caused to oxidative stress in brain of female rat and suggested that ovarian sex hormones have protective role in the prevention of oxidative stress $[20,21]$. Borras et al. founded an increase in lipid peroxidation and a decrease in glutathione levels in liver and brain mitochondria of ovariectomized rats. In addition, they reported that antioxidant gene expression was increased and oxidative damage was decreased in mitochondria of females than males [20,22]. Muthusami et al. showed that ovariectomy in rats reduced femur antioxidant enzymes and they elucidated this result by heightened lipid peroxidation after ovariectomy [20,23]. Yalın et al. indicated 
that ovariectomy reduced CAT and SOD activities and increased MDA levels both in liver and kidney tissues [20]. Sreelathakumari et al. showed increased MDA level and decreased CAT and SOD activity in liver of ovariectomized rats [24].

In the Ovx-CAL group, MDA level increased in liver and kidney tissues. Conversely, CAT activity decreased in liver but not in kidney compared to control groups. In the comparison of the Ovx and Ovx-CAL groups, we found that liver MDA level was significantly higher and CAT activity was significantly lower in the Ovx-CAL group than those of the Ovx group. Kidney MDA level was significantly higher but no significant variation in CAT activity was observed between Ovx and Ovx-CAL groups. These results showed us that calcitonin treatment didn't decrease lipid peroxidation besides this, increased oxidative stress in post-menopausal osteoporosis model.

Pharmaceuticals used in post-menopausal osteoporosis treatment could change the level of lipid peroxidation and antioxidant activity. Dombrecht et al. demonstrated that lipid peroxidation was reduced after treatment of risedronate together with some other bisphosphonates [25-27]. Ozgonul et al. indicated that brain lipid peroxidation level in ovariectomized rats decreased to normal value by raloxifene administration $[27,28]$. But there is no data on the effect of post-menopausal calcitonin treatment on oxidative stress $[7,8,29,30]$.

As a result, ovariectomy plays a vital role on oxidative stress on tissues and current state induces postmenopausal bone loss and triggers the osteoporosis formation, dramatically. As an opinion, anti-osteoporotic drugs may have an effect on decreasing the oxidative stress [27]. But calcitonin treatment couldn't prevent the oxidative stress on osteoporotic subjects and besides this increase it upwardly.

Further research requires displaying the oxidative stress mechanisms in more tissues and with more parameters. In addition to lipid peroxidation level, antioxidant activity can be used for following the prognosis of post-menopausal osteoporosis and osteoporosis treatment [27]. According to our data it is possible to say that contrary to expectations, calcitonin couldn't reduce the oxidative stress in postmenopusal osteoporosis, in fact it increased dramatically. And finally we can suggest that other post-menopausal osteoporosis preventing agents (such as vitamin and mineral supplementations, hormone replacement therapy, bisphosphonates, and selective estrogen receptor modulators, fluoride supplementation) may be preferred for osteoporosis treatment or if calcitonin must be used for several medical excuses, oxidative stress parameters should be followed during the therapy.

\section{References}

[1]. Song, Y.; Liebschner, M. A.; Gunaratne, G. H. Biophys. J. 2004, 87, 36423647.

[2]. Grynpas, M. D.; Huckell, B.; Pritzker, K. P.; Hancock, R. G.; Kessler, M. J. P. R. Health Sci. J. 1989, 8, 197-204.

[3]. Recker, R. R. Proc. Soc. Exp. Biol. Med. 1989, 191, 272-274.

[4]. Khosla, S. J. Clin. Endocrinol. Metab. 2010, 95, 3-10.

[5]. Davidson, M. R. J. Midwifery Wom. Heal. 2003, 48, 39-52.

[6]. Theodorou, D. J.; Theodorou, S. J.; Sartoris, D. J. Compr. Ther. 2002, 28, 109-122.

[7]. Pazzaglia, U. E.; Zatti, G.; Di Nucci, A.; Coci, A. Calcif. Tissue Int. 1993, 52, 125-129.

[8]. Plosker, G. L.; McTavish, D. Drugs Aging. 1996, 8, 378-400.

[9]. Mehta, N. M.; Malootian, A.; Gilligan, J. P. Curr. Pharm. Des. 2003, 9, 2659-2676.

[10]. El-Hajj Fuleihan, G. J. Med. Liban. 1998, 46, 23-28.

[11]. Rizer, M. K. Prim. Care. 2006, 33, 943-951.

[12]. Hawker, G. A. J. Rheumatol. Suppl. 1996, 45, 2-5.

[13]. Kulak, C. A.; Bilezikian, J. P. Int. J. Fertil. Womens Med. 1998, 43, 56-64.

[14]. Rao, L. G. Endocrinology Rounds. 2005, 5, 7-12.

[15]. Rao, L. G.; Guns, E.; Rao, A. V. Agro. Food Ind. Hi Tec. 2003, 14, 25-30,

[16]. Yalin, S.; Bagis, S.; Polat, G.; Dogruer, N.; Cenk, Aksit, S.; Hatungil, R.; Erdogan, C. Clin. Exp. Rheumatol. 2005, 23, 689-692.
[17]. Yagi, K. Methods Mol. Biol. 1998, 108, 101-106.

[18]. Aebi, H. Methods Enzymol. 1984, 105, 121-126.

[19]. Lowry, O. H.; Rosebrough, N. J.; Farr, A. L.; Randall, R. J. J. Biol. Chem 1951, 193, 265-275

[20]. Yalin, S.; Comelekoglu, U.; Bagis, S.; Sahin, N. O.; Ogenler, O.; Hatungil, R. Ecotoxicol. Environ. Saf. 2006, 65, 140-144.

[21]. Kume-Kick, J.; Ferris, D. C.; Russo-Menna, I.; Rice, M. E. Brain Res. 1996, 738, 8-14.

[22]. Borrás, C.; Sastre, J.; García-Sala, D.; Lloret, A.; Pallardó, F. V.; Viña, J. Free Radic. Biol. Med. 2003, 34, 546-552.

[23]. Muthusami, S.; Ramachandran, I.; Muthusami, B.; Vasudevan, G.; Prabhu, V.; Subramaniam, V.; Jagadeesan, A.; Narasimhan, S. Clin. Chim. Acta. 2005, 360, 81-86.

[24]. Sreelathakumari, K. T., Menon, V. P.; Leelamma, S. Indian J. Med. Res. 1993, 98, 305-308.

[25]. Dombrecht, E. J.; Cos, P.; Vanden, Berghe, D.; Van Offel, J. F.; Schuerwegh, A. J.; Bridts, C. H.; Stevens, W. J.; De Clerck, L.S. Biochem. Biophys. Res. Commun. 2004, 314, 675-680.

[26]. Dombrecht, E. J.; De Tollenaere, C. B.; Aerts, K.; Cos, P.; Schuerwegh, A J.; Bridts, C. H.; Van Offel, J. F.; Ebo, D. G.; Stevens, W. J.; De Clerck, L. S. Biochem. Biophys. Res. Commun. 2006, 348, 459-464.

[27]. Ozgocmen, S.; Kaya, H.; Fadillioglu, E.; Yilmaz, Z. Arch. Med. Res. 2007, 38, 196-205.

[28]. Ozgonul, M.; Oge, A.; Sezer, E. D.; Bayraktar, F.; Sozmen, E. Y. Endocr. Res. 2003, 29, 183-189.

[29]. Karsdal, M. A.; Henriksen, K.; Arnold, M.; Christiansen, C. BioDrugs. 2008, 22, 137-144.

[30]. Chesnut, C. H.; Azria, M.; Silverman, S.; Engelhardt, M.; Olson, M.; Mindeholm, L. Osteoporos. Int. 2008, 19, 479-491. 